\title{
The Spectrophotometric Multicomponent Analysis of a Ternary Mixture of Paracetamol, Aspirin, and Caffeine by the Double Divisor-Ratio Spectra Derivative Method
}

\author{
Reza Hajian $^{1}$ and Ahmad Soltaninezhad ${ }^{2}$ \\ ${ }^{1}$ Young Researchers Club, Gachsaran Branch, Islamic Azad University, 7581863876 Gachsaran, Iran \\ ${ }^{2}$ Chemistry Department, Gachsaran Branch, Islamic Azad University, 7581863876 Gachsaran, Iran \\ Correspondence should be addressed to Reza Hajian; hajian@iaug.ac.ir
}

Received 25 October 2012; Accepted 10 December 2012

Academic Editor: Roohollah Torabi Kachoosangi

Copyright (c) 2013 R. Hajian and A. Soltaninezhad. This is an open access article distributed under the Creative Commons Attribution License, which permits unrestricted use, distribution, and reproduction in any medium, provided the original work is properly cited.

\begin{abstract}
Double divisor-ratio spectra derivative method based on the spectrophotometric data was developed for the simultaneous analysis of a ternary mixture containing paracetamol, aspirin, and caffeine, without prior separation. This method is based on the use of the derivative of the ratio spectrum obtained by dividing the absorption spectrum of the ternary mixture by a standard spectrum of a mixture of two of the three compounds in the title mixture. The concentrations of three compounds in their mixture are determined by using their respective calibration graphs which are obtained by measuring the amplitude at either the maximum or minimum wavelengths selected. The selected wavelengths for determination of aspirin, caffeine, and paracetamol are 241.5, 256, and 258.5 nm, respectively. All of the solutions adjusted to $\mathrm{pH} 11$ before recording the spectra in the range of 220 to $320 \mathrm{~nm}$. Also, the mathematical explanation of the procedure is illustrated. The method was applied for the assay of Excedrin containing paracetamol, aspirin, and caffeine.
\end{abstract}

\section{Introduction}

For the simultaneous determination of two or more active compounds in the same mixtures without a separation step, several spectrophotometric methods, such as classical derivative spectrophotometry [1-4], Vierordt's method [5] and its modified version [6], orthogonal function method [7], dual wavelength spectrophotometry [8-10], $\mathrm{pH}$-induced differential spectrophotometry [11], the least square method [12], the multicomponent analysis program [13, 14] and a method, and multiwavelength linear regression analysis (MLRA) which was referred to by Blanco and co-workers [15] have been utilized.

Salinas et al. [16] and Nevado et al. [17] developed two methods for the resolution of two or more compounds in mixtures by ratio spectra derivative spectrophotometry and the derivative ratio spectra-zero crossing method. Salinas' method is based on the use of the derivative of the ratio spectra for a binary mixture. The absorption spectrum of the mixture is divided by the absorption spectrum of one of the compounds, and the first derivative of the ratio spectrum is obtained. The concentrations of active compounds are then determined from the calibration graphs obtained by measuring the amplitudes at points corresponding to the minimum or maximum wavelengths. In Berzas Nevado's method, the simultaneous determinations of three compounds in ternary mixtures are based on the measurements of the amplitude at the zero crossing points in the derivative spectrum of the ratio spectra.

In the present research, a sensitive, selective, accurate, and inexpensive procedure was applied for simultaneous determination of paracetamol (PAR), aspirin (ASP), and caffeine (CAF) by double divisor-ratio spectra derivative method with simultaneous standard additions of three analytes. This method is a novel standard addition method based on the derivative of the ratio spectra concept. In this 
paper, an attempt was made to calculate the derivative of the double divisor-ratio spectra and attribute them to the analyte concentration using spectrophotometry technique.

\section{Experimental}

2.1. Reagents. Paracetamol, aspirin, and caffeine were kindly provided by the Iranian Pharmaceutical Companies (Tehran, Iran). Analytical grade phosphoric acid, boric acid, acetic acid, and sodium hydroxide were supplied from Merck (Darmstadt, Germany). All other reagents were of analytical grade. Britton-Robinson (B-R) buffer $\left(0.1 \mathrm{~mol} \mathrm{~L}^{-1}\right)$ in the $\mathrm{pH}$ range of 2-10 was used throughout.

A $1.0 \times 10^{-3} \mathrm{~mol} \mathrm{~L}^{-1}$ paracetamol solution was prepared daily by dissolving $0.0074 \mathrm{~g}$ PAR (99.0\%) in ethanol (96\%) and was diluted in a $100 \mathrm{~mL}$ volumetric flask to the mark. A $1.0 \times 10^{-3} \mathrm{~mol} \mathrm{~L}^{-1}$ aspirin solution was prepared daily by dissolving $0.0090 \mathrm{~g}$ of ASP (99.5\%) in ethanol (96\%) and diluted in a $100 \mathrm{~mL}$ volumetric flask. A $1.0 \times 10^{-3} \mathrm{~mol} \mathrm{~L}^{-1}$ caffeine solution was prepared daily by dissolving $0.0097 \mathrm{~g}$ of CAF (99.5\%) in double distilled water and diluted into a $100 \mathrm{~mL}$ volumetric flask. These solutions were kept in a refrigerator at $4^{\circ} \mathrm{C}$ in dark. More dilute solutions were prepared by serial dilutions with double distilled water.

2.2. Instrumentation and Software. UV-visible absorption spectra were recorded by a spectrophotometer (Perkin Elmer) model Lambda 25, with the use of $1.0 \mathrm{~cm}$ quartz cells.

A Pentium IV $(2.53 \mathrm{GHz})$ computer controlled all the setting and data processing. The spectrum of each solution were recorded in the wavelength range of $200-320 \mathrm{~nm}$ and saved as text files. Double divisor-ratio derivative spectra calculated in Excel (2007) program.

A pH-meter (Metrohm, Model 827) with a double junction glass electrode was used to adjust the $\mathrm{pH}$ of the solutions.

2.3. Preparation of Real Samples. To assay Excedrin tablet containing paracetamol (325 mg), aspirin (325 mg), and caffeine $(65 \mathrm{mg})$ in each tablet, the content of five tablets are mixed together. The quantity of $0.0203 \mathrm{~g}$ of the powder was accurately weighted and then dissolved in $100 \mathrm{~mL}$ of ethanol (96\%). After being mixed completely, the solution was diluted to the mark with ethanol. This solution was kept in refrigerator at $4^{\circ} \mathrm{C}$.

2.4. General Procedure. The general procedure for the analysis of PAR, ASP, and CAF in a ternary mixture was as follows. To approximately $1.0 \mathrm{~mL}$ of sample solution in a $10.0 \mathrm{~mL}$ volumetric flask, $1.0 \mathrm{~mL}$ B- $\mathrm{R}$ buffer $(\mathrm{pH} \mathrm{11.0)}$ is added, and the final volume was diluted to the mark with double distilled water after successive standard additions of the three components (PAR, IBU, and CAF) at the same mole ratio. For simultaneous determination of PAR, ASP, and CAF, the spectra of ternary mixture after each standard addition divided to the standard binary samples of ASP + $\mathrm{CAF}, \mathrm{CAF}+\mathrm{PAR}$, and PAR + ASP in the same concentrations of $2.0 \mu \mathrm{mol} \mathrm{L}{ }^{-1}$ for each species. Then the ratio spectra were transformed to Matlab software and converted to derivative

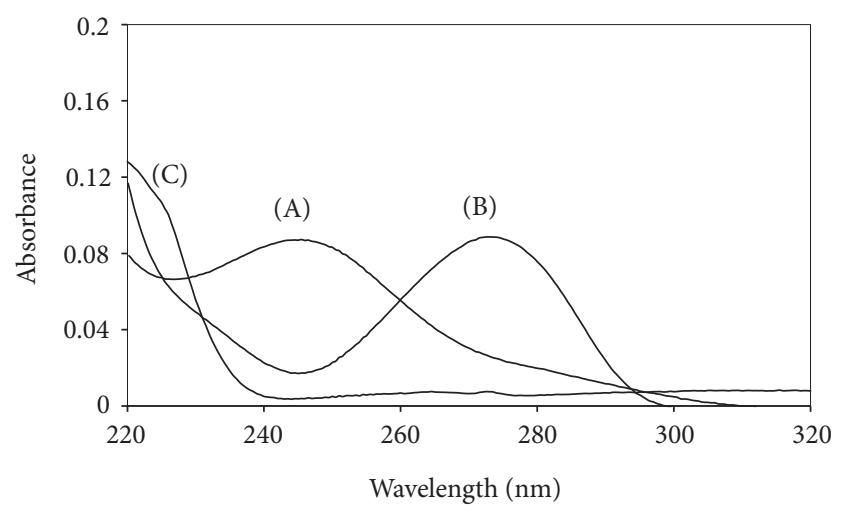

FIGURE 1: Absorption spectra of aspirin, $50 \mu \mathrm{mol} \mathrm{L}^{-1}$ (a); caffeine, $20 \mu \mathrm{mol} \mathrm{L}^{-1}$ (b), paracetamol, $20 \mu \mathrm{mol} \mathrm{L}^{-1}$ (c) at B-R buffer pH 11.0.

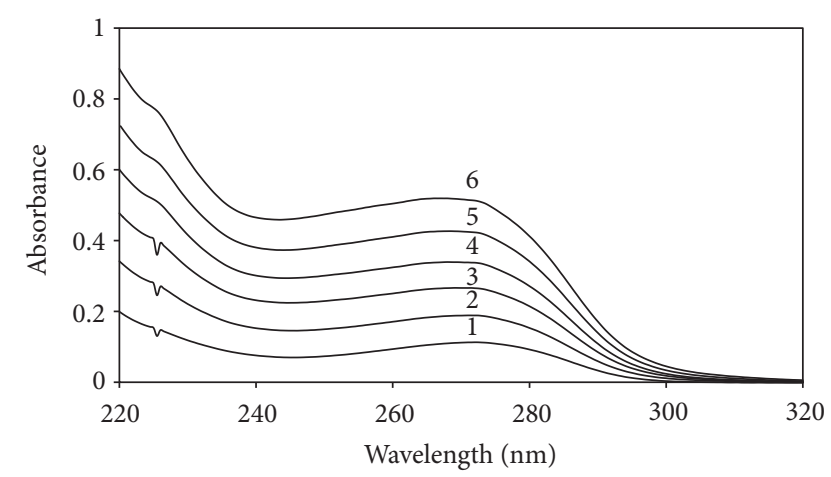

FIgURE 2: The spectra of the ternary mixture after addition of standards ASP, CAF, and PAR in the same mole ratios in the concentration range of $10-60 \mu \mathrm{mol} \mathrm{L}^{-1}$ for spectra $1-6$. The initial solution contains a ternary mixture of ASP $\left(50 \mu \mathrm{mol} \mathrm{L}^{-1}\right)$, CAF $\left(20 \mu \mathrm{mol} \mathrm{L}^{-1}\right)$, and PAR $\left(20 \mu \mathrm{mol} \mathrm{L}^{-1}\right)$.

ratio spectra, and the values of PAR, ASP, and CAF in the ternary mixtures were determined by standard addition plots at wavelengths $258.5,241.5$, and $256 \mathrm{~nm}$, respectively.

For better understanding this phenomenon, let us consider a mixture of PAR, ASP, and CAF in the same concentration of $10.0 \mu \mathrm{mol} \mathrm{L}^{-1}$ for each component. To determine ASP in the presence of PAR and CAF, the absorption spectra of the ternary mixture, after successive standard additions of three components, were prepared (Figure 2) and divided by the spectrum of the standard mixture solution of PAR and CAF $\left(2.0 \mu \mathrm{mol} \mathrm{L}^{-1}\right.$ each in B-R buffer), and the ratio spectra were plotted (Figure 3). The first derivatives of the ratio spectra were plotted with $\Delta \lambda=5 \mathrm{~nm}$ (Figure 4). The amount of ASP was determined by measuring the amplitude at $241.5 \mathrm{~nm}$ corresponding to a minimum in the first derivative of the ratio spectra in the spectral region selected (Figure 5).

2.5. Double Divisor-Ratio Spectra Derivative Method. As shown in Figure 1, the absorption spectra of paracetamol, aspirin, and caffeine overlapped in the wavelength range of 220-320 nm. Therefore, double divisor-ratio spectra derivative method proposed for simultaneous determination of 


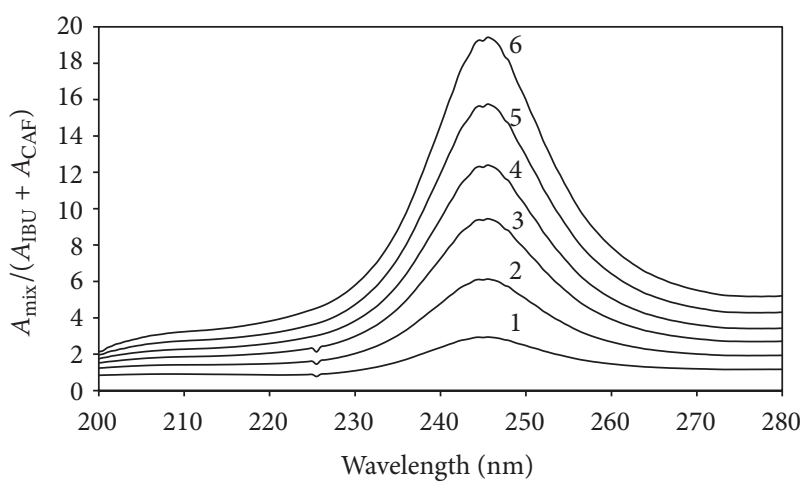

Figure 3: Double divisor of the ratio spectra for a ternary mixture of aspirin, caffeine, and paracetamol after simultaneous standard addition of three components in the concentration range of $10-60 \mu \mathrm{mol} \mathrm{L}^{-1}(1-6)$. Double divisors concentrations are CAF, $2.0 \mu \mathrm{mol} \mathrm{L}^{-1}+$ PAR, $2.0 \mu \mathrm{mol} \mathrm{L}^{-1}$. All of the conditions are as Figure 2 .

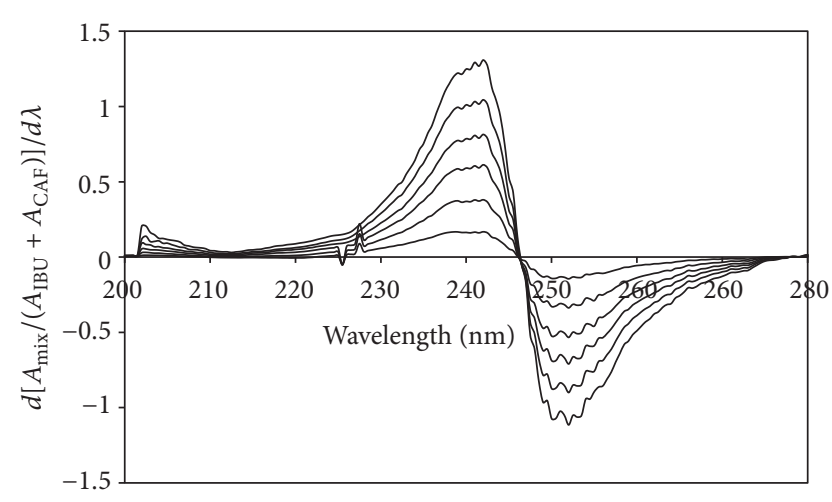

FigURE 4: First-derivative double divisor-ratio spectra for a ternary mixture of aspirin, caffeine, and paracetamol after simultaneous standard addition of three components in the concentration range of $10-60 \mu \mathrm{mol} \mathrm{L}^{-1} . \Delta \lambda=5.0 \mathrm{~nm}$. All of the conditions are as Figure 3 .

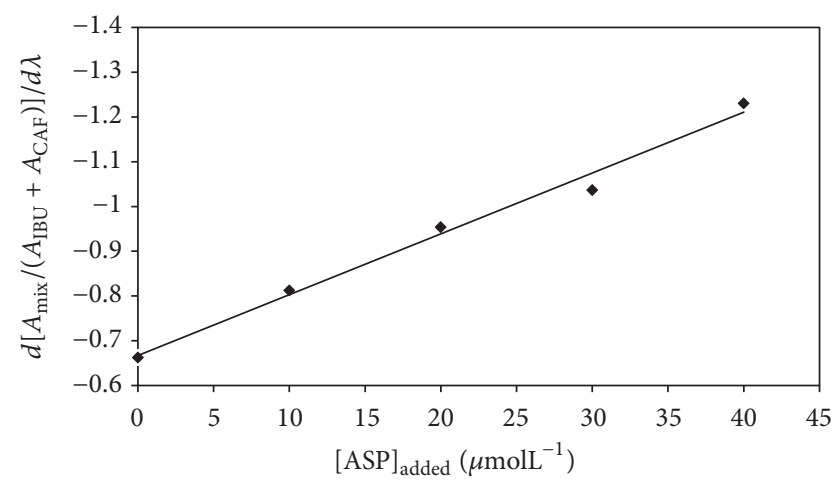

FIgURE 5: Standard addition plot for the derivative of double divisorratio spectra for a mixture of ASP $\left(50 \mu \mathrm{mol} \mathrm{L}^{-1}\right), \operatorname{CAF}\left(20 \mu \mathrm{mol} \mathrm{L}^{-1}\right)$, and PAR $\left(20 \mu \mathrm{mol} \mathrm{L}^{-1}\right)$ after standard addition of three components in the same mole ratios in the concentration range of $10-60 \mu \mathrm{mol} \mathrm{L}^{-1}$. The initial solution contains a ternary mixture of $\operatorname{ASP}\left(50 \mu \mathrm{mol} \mathrm{L}^{-1}\right), \operatorname{CAF}\left(20 \mu \mathrm{mol} \mathrm{L}^{-1}\right)$, and PAR $\left(20 \mu \mathrm{mol} \mathrm{L}^{-1}\right)$. compounds in ternary samples. If Beer's law is obeyed for all compounds over the whole wavelength range used, and if the path length is $1 \mathrm{~cm}$, the absorption spectrum of the ternary mixture can be written in the form of the following equation:

$$
A_{m, \lambda_{i}}=\varepsilon_{\mathrm{PAR}, \lambda_{i}} C_{\mathrm{PAR}}+\varepsilon_{\mathrm{ASP}, \lambda_{i}} C_{\mathrm{ASP}}+\varepsilon_{\mathrm{CAF}, \lambda_{i}} C_{\mathrm{CAF}},
$$

where $A_{m, \lambda_{i}}$ is the absorbance of the mixture at wavelength $\lambda_{i}$, and $\varepsilon_{\mathrm{PAR}}, \varepsilon_{\mathrm{ASP}}$, and $\varepsilon_{\mathrm{CAF}}$ are the absorptivities of PAR, ASP and CAF, respectively. A similar equation for two compounds in the same ternary mixture as in a standard binary mixture can be written as

$$
A_{m, \lambda_{i}}=\varepsilon_{\mathrm{ASP}, \lambda_{i}} C_{\mathrm{ASP}}^{0}+\varepsilon_{\mathrm{CAF}, \lambda_{i}} C_{\mathrm{CAF}}^{0} .
$$

If (1) is divided by (2) corresponding to the spectrum of a standard solution of two of the components in the ternary mixture, the ratio spectrum is obtained in

$$
\begin{aligned}
\frac{A_{m, \lambda_{i}}}{\varepsilon_{\mathrm{ASP}, \lambda_{i}} C_{\mathrm{ASP}}^{0}+\varepsilon_{\mathrm{CAF}, \lambda_{i}} C_{\mathrm{CAF}}^{0}}= & \frac{\varepsilon_{\mathrm{ASP}, \lambda_{i}} C_{\mathrm{ASP}}+\varepsilon_{\mathrm{CAF}, \lambda_{i}} C_{\mathrm{CAF}}}{\varepsilon_{\mathrm{ASP}, \lambda_{i}} C_{\mathrm{ASP}}^{0}+\varepsilon_{\mathrm{CAF}, \lambda_{i}} C_{\mathrm{CAF}}^{0}} \\
& +\frac{\varepsilon_{\mathrm{PAR}} C_{\mathrm{PAR}}}{\varepsilon_{\mathrm{ASP}, \lambda_{i}} C_{\mathrm{ASP}}^{0}+\varepsilon_{\mathrm{CAF}, \lambda_{i}} C_{\mathrm{CAF}}^{0}} .
\end{aligned}
$$

The ratio of the sum of $\varepsilon_{\mathrm{ASP}, \lambda_{i}} C_{\mathrm{ASP}}$ and $\varepsilon_{\mathrm{CAF}, \lambda_{i}} C_{\mathrm{CAF}}$ to the sum of $\varepsilon_{\mathrm{ASP}, \lambda_{i}} C_{\mathrm{ASP}}^{0}$ and $\varepsilon_{\mathrm{CAF}, \lambda_{i}} C_{\mathrm{CAF}}^{0}$ is equal to a constant $(k)$ with respect to $\lambda$, in a certain region or point of wavelength. These coinciding points of the derivative of the ratio spectra can be selected as working wavelengths for the determinations of the subject compounds in the ternary mixture. If the above constant is replaced in (3), we obtain

$$
\frac{A_{m, \lambda_{i}}}{\varepsilon_{\mathrm{ASP}, \lambda_{i}} C_{\mathrm{ASP}}^{0}+\varepsilon_{\mathrm{CAF}, \lambda_{i}} C_{\mathrm{CAF}}^{0}}=k+\frac{\varepsilon_{\mathrm{PAR}} C_{\mathrm{PAR}}}{\varepsilon_{\mathrm{ASP}, \lambda_{i}} C_{\mathrm{ASP}}^{0}+\varepsilon_{\mathrm{CAF}, \lambda_{i}} C_{\mathrm{CAF}}^{0}} .
$$

However, if the standard concentrations of $C_{\mathrm{ASP}}^{0}$ and $C_{\mathrm{CAF}}^{0}$ in (2) are equal or very close to each other, we could write

$$
\varepsilon_{\mathrm{ASP}, \lambda_{i}} C_{\mathrm{ASP}}^{0}+\varepsilon_{\mathrm{CAF}, \lambda_{i}} C_{\mathrm{CAF}}^{0}=C_{\mathrm{CAF}}^{0}\left[\varepsilon_{\mathrm{ASP}, \lambda_{i}}+\varepsilon_{\mathrm{CAF}, \lambda_{i}}\right] .
$$

Substituting (5) into (4), (6) is derived as follows:

$$
\frac{A_{m, \lambda_{i}}}{\varepsilon_{\mathrm{ASP}, \lambda_{i}} C_{\mathrm{ASP}}^{0}+\varepsilon_{\mathrm{CAF}, \lambda_{i}} C_{\mathrm{CAF}}^{0}}=k+\frac{\varepsilon_{\mathrm{PAR}_{i}} C_{\mathrm{PAR}}}{C_{\mathrm{CAF}}^{0}\left[\varepsilon_{\mathrm{ASP}, \lambda_{i}}+\varepsilon_{\mathrm{CAF}, \lambda_{i}}\right]} .
$$

If the first derivative of (6) is taken, since the derivative of a constant is zero, (7) will be obtained as follows:

$$
\begin{aligned}
& \frac{d}{d \lambda}\left[\frac{A_{m, \lambda_{i}}}{C_{\mathrm{CAF}}^{0}\left[\varepsilon_{\mathrm{ASP}, \lambda_{i}}+\varepsilon_{\mathrm{CAF}, \lambda_{i}}\right]}\right] \\
& =\frac{d}{d \lambda}\left[\frac{\varepsilon_{\mathrm{PAR}}}{\left(\varepsilon_{\mathrm{ASP}, \lambda_{i}}+\varepsilon_{\mathrm{CAF}, \lambda_{i}}\right)}\right] \frac{C_{\mathrm{PAR}}}{C_{\mathrm{CAF}}^{0}} .
\end{aligned}
$$




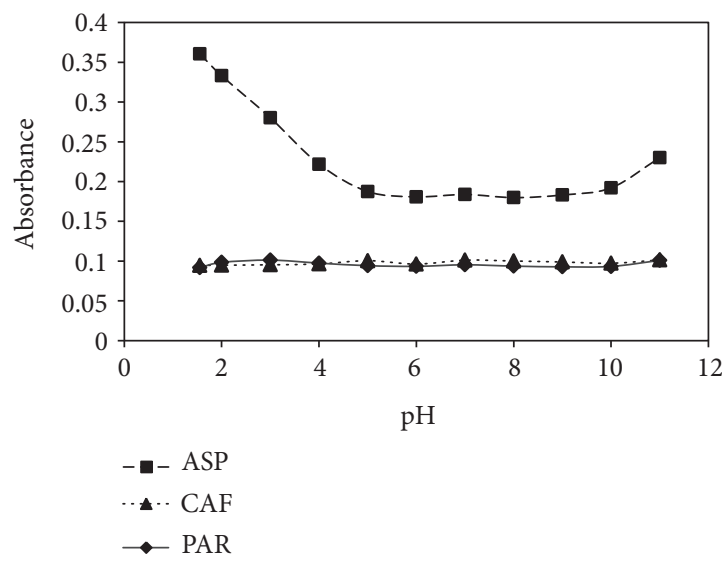

(a)

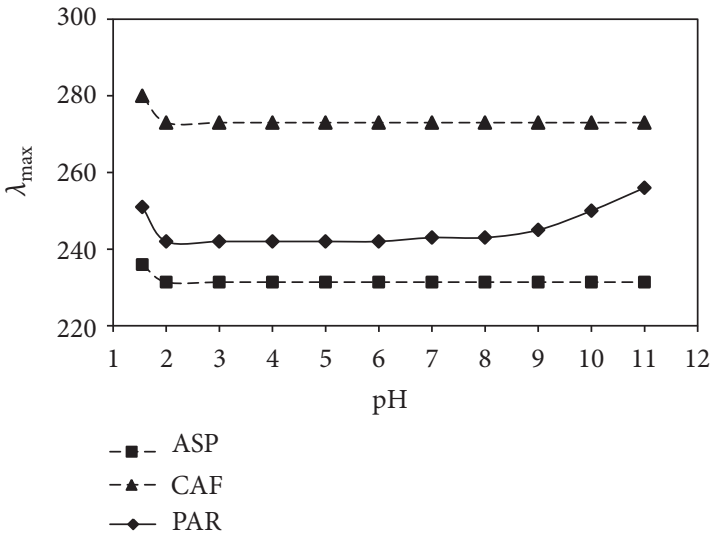

(b)

FIgURE 6: Effect of $\mathrm{pH}$ on the sensitivity (a) and selectivity (b) of the spectra of ASP, CAF, and PAR. All of the conditions are as Figure 1.

TABLE 1: Replicative determination of paracetamol, aspirin, and caffeine in some ternary mixtures by double divisor-ratio spectra derivative method.

\begin{tabular}{|c|c|c|c|c|c|c|c|c|c|}
\hline \multirow{2}{*}{ Mixture } & \multicolumn{3}{|c|}{ Added $\left(\mu \mathrm{mol} \mathrm{L}^{-1}\right)$} & \multicolumn{3}{|c|}{ Found $\left(\mu \mathrm{mol} \mathrm{L}^{-1}\right)$} & \multicolumn{3}{|c|}{ RSD (\%) } \\
\hline & PAR & ASP & CAF & PAR & ASP & CAF & PAR & ASP & CAF \\
\hline \multirow{3}{*}{1} & 30 & 30 & 30 & 29.08 & 28.81 & 31.06 & \multirow{3}{*}{2.58} & \multirow{3}{*}{1.88} & \multirow{3}{*}{2.74} \\
\hline & 30 & 30 & 30 & 28.94 & 29.19 & 30.91 & & & \\
\hline & 30 & 30 & 30 & 30.32 & 29.90 & 29.54 & & & \\
\hline \multirow{3}{*}{2} & 30 & 50 & 40 & 32.01 & 48.70 & 38.84 & \multirow{3}{*}{3.30} & \multirow{3}{*}{1.42} & \multirow{3}{*}{1.54} \\
\hline & 30 & 50 & 40 & 30.03 & 50.01 & 38.07 & & & \\
\hline & 30 & 50 & 40 & 31.50 & 49.80 & 39.50 & & & \\
\hline \multirow{3}{*}{3} & 20 & 8 & 10 & 18.08 & 8.08 & 10.10 & \multirow{3}{*}{4.56} & \multirow{3}{*}{0.58} & \multirow{3}{*}{5.73} \\
\hline & 20 & 8 & 10 & 21.93 & 7.99 & 9.98 & & & \\
\hline & 20 & 8 & 10 & 20.90 & 8.01 & 9.08 & & & \\
\hline
\end{tabular}

Equation (7) is the mathematical foundation of multicomponent analysis which permits the determination of the concentration of each of the active compounds in solution without interference from the other components of the ternary system. In practice, (7) corresponding to the first derivative ratio spectrum of PAR is obtained by dividing the absorption spectrum of the ternary mixture of PAR, ASP, and CAF by the standard spectrum of two of the compounds in the ternary mixture. Also, in (7), the derivative signal of the ratio spectrum of the ternary mixture is dependent only on the concentration values of PAR and $C_{\mathrm{CAF}}^{0}$, but is independent of the concentration values $C_{\mathrm{ASP}}$ and $C_{\mathrm{CAF}}$ in the ternary mixture. In the developed method, the concentration of $C_{\mathrm{PAR}}$ in the ternary mixture is proportional to the first derivative signals corresponding to a maximum or minimum point.

The double divisor spectra of binary mixtures calculated as the following steps.

(a) A standard binary mixture of analytes added to the unknown sample and recorded its spectrum.

(b) The spectrum of unknown sample recorded in the wavelength range of 220 to $320 \mathrm{~nm}$. (c) The spectrum of double divisor in the presence of matrix effect calculated by the subtract the spectrum of step "b" from step "a".

The stored spectra of the ternary mixture are divided by the spectrum of double divisors after addition of pure PAR using MATLAB software. The derivative of the ratio spectra at wavelength $258.5 \mathrm{~nm}$ plotted against standard concentrations of PAR. As explained here, this technique can be used for determination of other compounds in the ternary mixture using other double divisors containing PAR + CAF and PAR + ASP for the determination of ASP and CAF, respectively. In this research, simultaneous standard additions of three compounds of PAR, ASP, and CAF into the ternary mixture presented, and the analysis of PAR, ASP and CAF is also applicable using the doubled divisor-ratio derivative method for the first time. This technique is very simple and fast in comparison with the individual standard addition method.

\section{Results and Discussions}

The absorption spectra of the three compounds, PAR, ASP, and CAF overlapped closely in the region $220-320 \mathrm{~nm}$ in Figure 1. For this reason, the determination of the above 
TABLE 2: Determination of aspirin, caffeine, and paracetamol in some ternary mixtures.

\begin{tabular}{lccccccccc}
\hline \multirow{2}{*}{ Mixture } & \multicolumn{3}{c}{ Added $\left(\mu \mathrm{mol} \mathrm{L}^{-1}\right)$} & \multicolumn{3}{c}{ Found $\left(\mu \mathrm{mol} \mathrm{L}^{-1}\right)$} & \multicolumn{3}{c}{ Recovery $(\%)$} \\
& ASP & CAF & PAR & ASP & CAF & PAR & ASP & CAF \\
\hline 1 & 20.0 & 30.0 & 40.0 & 19.90 & 29.85 & 40.17 & 99.5 & 99.5 \\
2 & 20.0 & 10.0 & 10.0 & 19.71 & 9.90 & 10.07 & 98.55 & 99.00 & 100.43 \\
3 & 10.0 & 20.0 & 8.0 & 10.00 & 19.58 & 8.03 & 100.0 & 97.90 & 100.38 \\
4 & 30.0 & 10.0 & 8.0 & 29.85 & 10.00 & 8.01 & 99.50 & 100.00 & 100.13 \\
5 & 40.0 & 20.0 & 30.0 & 39.28 & 19.96 & 30.33 & 98.20 & 99.80 & 101.10 \\
6 & 50.0 & 50.0 & 50.0 & 15.17 & 50.74 & 50.00 & 30.34 & 101.48 & 100.00 \\
7 & 60.0 & 30.0 & 30.0 & 60.22 & 30.01 & 31.01 & 100.37 & 100.03 & 103.37 \\
8 & 70.0 & 30.0 & 20.0 & 70.17 & 29.98 & 20.52 & 100.24 & 99.93 & 102.60 \\
9 & 10.0 & 10.0 & 10.0 & 9.98 & 10.36 & 10.70 & 99.80 & 103.60 & 107.00 \\
10 & 10.0 & 30.0 & 50.0 & 9.06 & 29.12 & 52.23 & 90.60 & 97.07 & 104.46 \\
\hline
\end{tabular}

TABLE 3: Determination of paracetamol, aspirin, and caffeine in Excedrin tablets by the proposed method.

\begin{tabular}{lccccccccc}
\hline \multirow{2}{*}{ Sample $^{*}$} & \multicolumn{3}{c}{ Added $(\mathrm{mg})$} & \multicolumn{3}{c}{ Found $(\mathrm{mg})$} & \multicolumn{3}{c}{ Recovery (\%) } \\
& PAR & ASP & CAF & PAR & ASP & CAF & PAR & ASP & CAF \\
\hline \multirow{2}{*}{ Brand I } & - & - & - & 325.78 & 66.50 & 331.51 & 100.24 & 102.30 & 102.00 \\
& 88.50 & 65.00 & 65.13 & 408.99 & 128.70 & 322.70 & 106.00 & 95.60 & 94.00 \\
\hline \multirow{2}{*}{ Brand II } & - & - & - & 329.48 & 66.95 & 328.93 & 101.37 & 103.00 & 101.20 \\
& 237.22 & 195.00 & 196.57 & 574.08 & 273.65 & 531.40 & 103.11 & 106.00 & 103.00 \\
\hline Average & & & & & & & 102.68 & 101.72 & 100.05 \\
RSD (\%) & & & & & & & 2.44 & 4.31 & 4.10 \\
\hline
\end{tabular}

* Brands 1 and 2 are Excedrin tablets containing paracetamol $(325 \mathrm{mg})$, aspirin $(325 \mathrm{mg})$, and caffeine $(65 \mathrm{mg})$ in each tablet from Bristol-Meys Squibb and Novartis Consumer Health companies for brands 1 and 2, respectively.

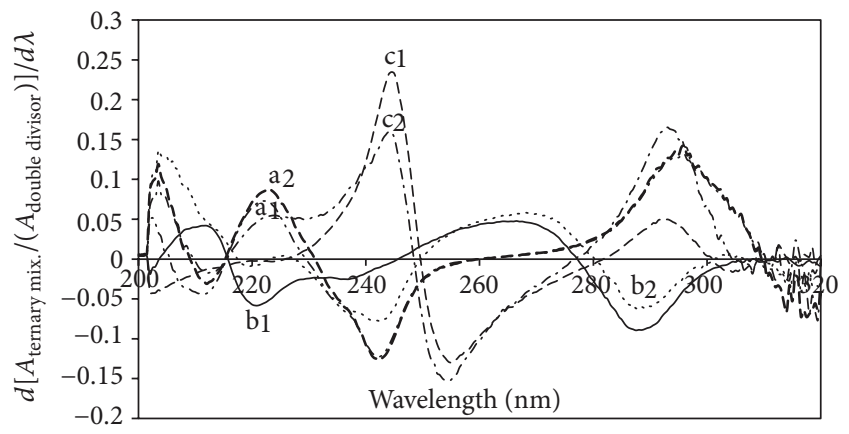

FIgURE 7: The coincident spectra of the first derivative of the ratio spectra of (a1) $20 \mu \mathrm{mol} \mathrm{L}^{-1}$ pure ASP and (a2) ternary mixture of $20 \mu \mathrm{mol} \mathrm{L}^{-1}$ ASP, $50 \mu \mathrm{mol} \mathrm{L}^{-1} \mathrm{CAF}, 20 \mu \mathrm{mol} \mathrm{L}{ }^{-1} \mathrm{PAR}$, and $2.0 \mu \mathrm{mol} \mathrm{L}{ }^{-1} \mathrm{CAF}+2.0 \mu \mathrm{mol} \mathrm{L}^{-1}$ PAR as a double divisor; (b1) $50 \mu \mathrm{mol} \mathrm{L}^{-1}$ pure CAF and (b2) ternary mixture of $20 \mu \mathrm{mol} \mathrm{L}^{-1}$ ASP, $50 \mu \mathrm{mol} \mathrm{L}{ }^{-1}$ CAF, $20 \mu \mathrm{mol} \mathrm{L}^{-1}$ PAR, and $2.0 \mu \mathrm{mol} \mathrm{L}^{-1} \mathrm{ASP}+$ $2.0 \mu \mathrm{mol} \mathrm{L}^{-1}$ PAR as a double divisor; and (c1) $20 \mu \mathrm{mol} \mathrm{L}^{-1}$ pure PAR and (c2) ternary mixture of $20 \mu \mathrm{mol} \mathrm{L}^{-1} \mathrm{ASP}, 50 \mu \mathrm{mol} \mathrm{L}^{-1} \mathrm{CAF}$, $20 \mu \mathrm{mol} \mathrm{L}{ }^{-1} \mathrm{PAR}$, and $2.0 \mu \mathrm{mol} \mathrm{L}^{-1} \mathrm{ASP}+2.0 \mu \mathrm{mol} \mathrm{L}^{-1} \mathrm{CAF}$ as a double divisor.

compounds was not possible from direct measurements of absorbances in the zero-order spectra. In this research, double divisor-ratio spectra derivative method based on the spectrophotometric data was developed for the simultaneous analysis of the ternary mixtures containing paracetamol, aspirin, and caffeine, without prior separation.

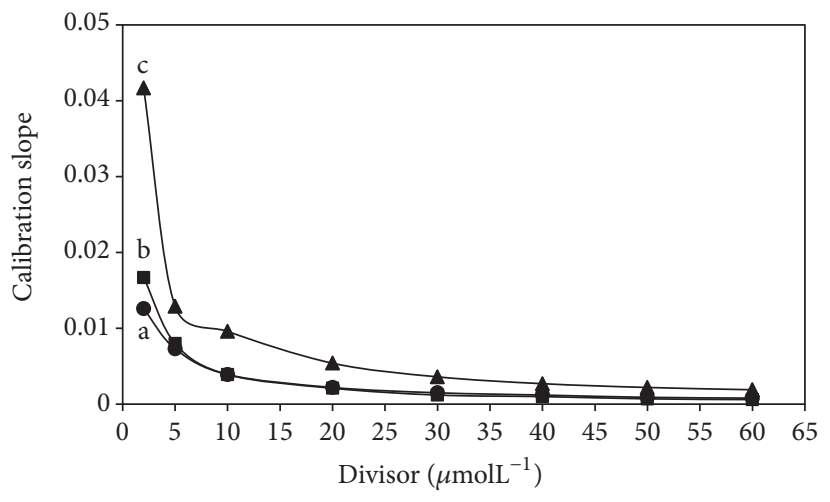

FIGURE 8: Effect of double divisor concentrations on the slopes of the calibration curves of (a) ASP, (b) CAF, and (c) PAR.

3.1. Optimization of the Parameters. In the following, the effective parameters involving $\mathrm{pH}$, working wavelengths, and double devisor concentrations studied on the accuracy of the proposed method.

3.1.1. Optimization of $p H$. It has been shown that the maximum absorbances for CAF and PAR are independent of the $\mathrm{pH}$ of the solution within the $\mathrm{pH}$ range of 1.8 to 11.0 in terms of sensitivity (Figure 6(a)). The maximum wavelengths for PAR and ASP are close to each other in the range of 1.8 to 8.0 but at $\mathrm{pH}>8.0$, overlapping spectra between PAR and 
ASP decreased, therefore B-R buffer at $\mathrm{pH} 11.0$ was selected to adjust the $\mathrm{pH}$ of solutions before recording the spectra.

3.1.2. Selection of the Working Wavelengths. In the application of this method, the first derivative of the ratio spectra of pure compound and its ternary mixture would be coincided in the spectral region corresponding to a maximum point or a minimum point of the wavelength as shown in Figure 7 . These coinciding points of the derivative of the ratio spectra can be selected as working wavelengths for the determinations of the subject compounds in the ternary mixture. The best working wavelengths selected at 258.5, 241.5, and $256 \mathrm{~nm}$ for determination of paracetamol, aspirin, and caffeine, respectively.

3.1.3. The Effect of Double Divisor Concentrations. According to the theory [16], the concentrations of double divisors should be equal, but the slope of the calibration graphs proportionally decreased by increasing concentrations of divisors (Figure 8). These results confirm the reliability of the ratio spectra method in the present instance. According to the above results, concentration of $2.0 \mu \mathrm{mol} \mathrm{L}^{-1}$ was chosen as the divisor concentrations.

3.2. Figures of Merit. To check the reproducibility of the proposed method, three replicate experiments for the determination of paracetamol, aspirin, and caffeine in ternary mixtures have been designed (Table 1). The relative standard deviation values are in the range of 0.58 to $5.73 \%$.

The limit of detection calculated as LOD $=3 S_{C}[18]$, where $S_{C}$ is the standard deviation of several $(n=3)$ replicated measurement of zero concentration of the analyte using the proposed method. The corresponding values obtained were $0.46,0.53$, and $0.68 \mu \mathrm{mol} \mathrm{L}^{-1}$ for PAR, ASP, and CAF, respectively.

The calibration plots were linear in the ranges of $0.4-320.0 \mu \mathrm{mol} \mathrm{L}^{-1}, \quad 0.8-160.0 \mu \mathrm{mol} \mathrm{L}^{-1}$, and $0.4-260.0$ $\mu \mathrm{mol} \mathrm{L}^{-1}$, respectively, for PAR, ASP, and CAF with the correlation coefficients of $0.9979,0.9999$, and 0.9991 .

3.3. Application of the Proposed Method in Synthetic and Real Samples. In order to evaluate the applicability of the proposed method for the determination of PAR, ASP, and CAF in real samples, the utility of the developed method was tested by determining of the compounds in several model (mixed) samples (Table 2) and pharmaceutical formulations (Table 3). The good recoveries of the spiked samples are indicative of the successful applicability of the proposed method for simultaneous determination of paracetamol, aspirin, and caffeine. All of the recoveries in real samples were satisfactory in the range of $94.0 \%$ to $106.0 \%$.

\section{Conclusions}

This work formulates a new approach to the simultaneous analysis of ternary mixtures of paracetamol, aspirin, and caffeine which have overlapping spectra. In the double divisor-ratio spectra derivative method, for each compound in ternary mixture, without searching for the critical point for the separated peaks, the maximum amplitude of the separated peaks can be measured. This can be considered as an advantage of the new method over alternative methods for the resolution of ternary mixtures. Our new method has great promise for the routine determination of two or more compounds in mixtures and for the analysis of Excedrin tablets in control process of products.

\section{Conflict of Interests}

It needs to be mentioned that the Merck materials (phosphoric acid, boric acid, acetic acid, and sodium hydroxide) were provided to the author by the Gachsaran Branch, Islamic Azad University where the author work as a member of the faculty, and these materials, which are running very low, have been purchased by the university around the year 2005 .

\section{Acknowledgments}

The authors gratefully acknowledge the support of this work by Islamic Azad University of Gachsaran and the assistance of Farabi Pharmaceutical Company for donation of pure compounds.

\section{References}

[1] A. T. Giese and C. S. French, "The analysis of overlapping spectral absorption bands by derivative spectrophotometry," Applied Spectroscopy, vol. 9, pp. 78-96, 1955.

[2] T. C. O’Haver and G. L. Green, "Numerical error analysis of derivative spectrometry for the quantitative analysis of mixtures," Analytical Chemistry, vol. 48, no. 2, pp. 312-318, 1976.

[3] T. C. O'Haver, "Derivative and wavelength modulation spectrometry," Analytical Chemistry, vol. 51, pp. 91A-100A, 1979.

[4] R. Rohilla and U. Gupta, "Simultaneous determination of cobalt (II) and nickel (II) by first order derivative spectrophotometry in micellar media," E-Journal of Chemistry, vol. 9, pp. 1357-1363, 2012.

[5] L. Heilmeyer, Spectrophotometry in Medicine, Adam Hilger, London, UK, 1943.

[6] A. L. Glenn, "The importance of extinction ratios in the spectrophotometric analysis of mixtures of two known absorbing substances.", The Journal of Pharmacy and Pharmacology, vol. 12, pp. 595-608, 1960.

[7] A. L. Glenn, "The use of orthogonal functions to correct for irrelevant absorption in two component spectrophotometric analysis," The Journal of Pharmacy and Pharmacology, vol. 15, pp. 123T-130T, 1963.

[8] S. Shibata, M. Furukawa, and K. Goto, "Dual-wavelength spectrophotometry. General method," Analytica Chimica Acta, vol. 46, no. 2, pp. 271-279, 1969.

[9] S. Shibata, M. Furukawa, and K. Goto, "Dual-wavelength spectrophotometry. The determination of mixtures," Analytica Chimica Acta, vol. 53, no. 2, pp. 369-377, 1971. 
[10] S. Shibata, K. Goto, and Y. Ishiguro, "Dual-wavelength spectrophotometry-part III. Determination of arsenazo I in arsenazo III," Analytica Chimica Acta, vol. 62, no. 2, pp. 305-310, 1972.

[11] A. M. Wahbi and A. M. Faraghaly, "Application of the $\Delta \mathrm{A}$ method to the determination of morphine," Journal of Pharmacy and Pharmacology, vol. 22, pp. 848-850, 1970.

[12] A. M. Wahbi, H. Abdine, M. A. Korany, and F. A. El-Yazbi, "Spectrophotometric analysis of binary mixtures of antazoline and naphazoline.", Journal of Pharmaceutical Sciences, vol. 67, no. 1, pp. 140-141, 1978.

[13] Y. R. Tahboub and H. L. Pardue, "Evaluation of multiwavelength first- and second-derivative spectra for the quantitation of mixtures of polynuclear aromatic hydrocarbons," Analytical Chemistry, vol. 57, no. 1, pp. 38-41, 1985.

[14] D. T. Rossi and H. L. Pardue, "Effects of wavelength range on the simultaneous quantitation of polynuclear aromatic hydrocarbons with absorption spectra," Analytica Chimica Acta, vol. 175, pp. 153-161, 1985.

[15] M. Blanco, J. Gene, H. Iturriaga, S. Maspoch, and J. Riba, "Diode-array detectors in flow-injection analysis Mixture resolution by multi-wavelength analysis," Talanta, vol. 34 , no. 12 , pp. 987-993, 1987.

[16] F. Salinas, J. J. B. Nevado, and M. A. Espinosa, "A new spectrophotometric method for quantitative multicomponent analysis resolution of mixtures of salicylic and salicyluric acids," Talanta, vol. 37, no. 3, pp. 347-351, 1990.

[17] J. J. B. Nevado, C. G. Cabanillas, and F. Salinas, "Spectrophotometric resolution of ternary mixtures of salicylaldehyde, 3-hydroxybenzaldehyde and 4-hydroxybenzaldehyde by the derivative ratio spectrum-zero crossing method," Talanta, vol. 39, no. 5, pp. 547-553, 1992.

[18] J. C. Miller and J. N. Miller, Statistics for Analytical Chemistry, Ellis Horwood, New York, NY, USA, 3rd edition, 1993. 

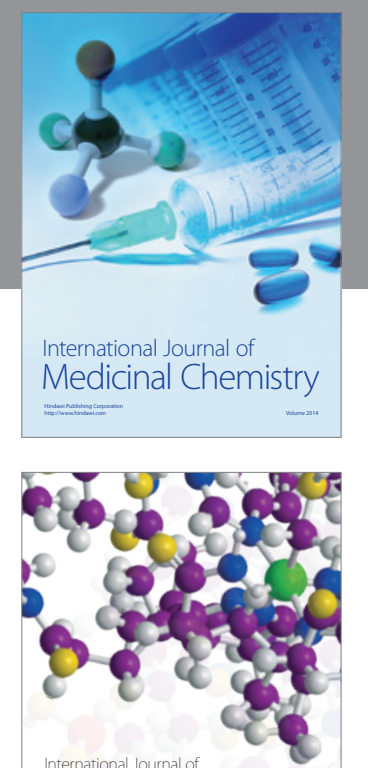

\section{Carbohydrate} Chemistry

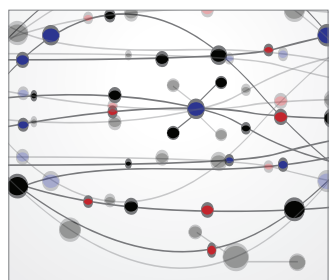

The Scientific World Journal
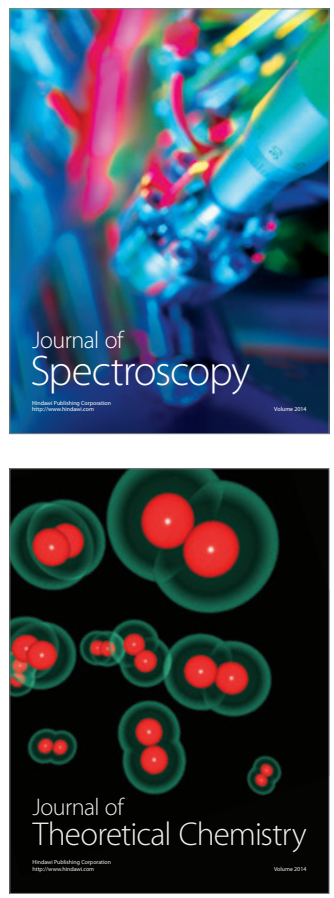
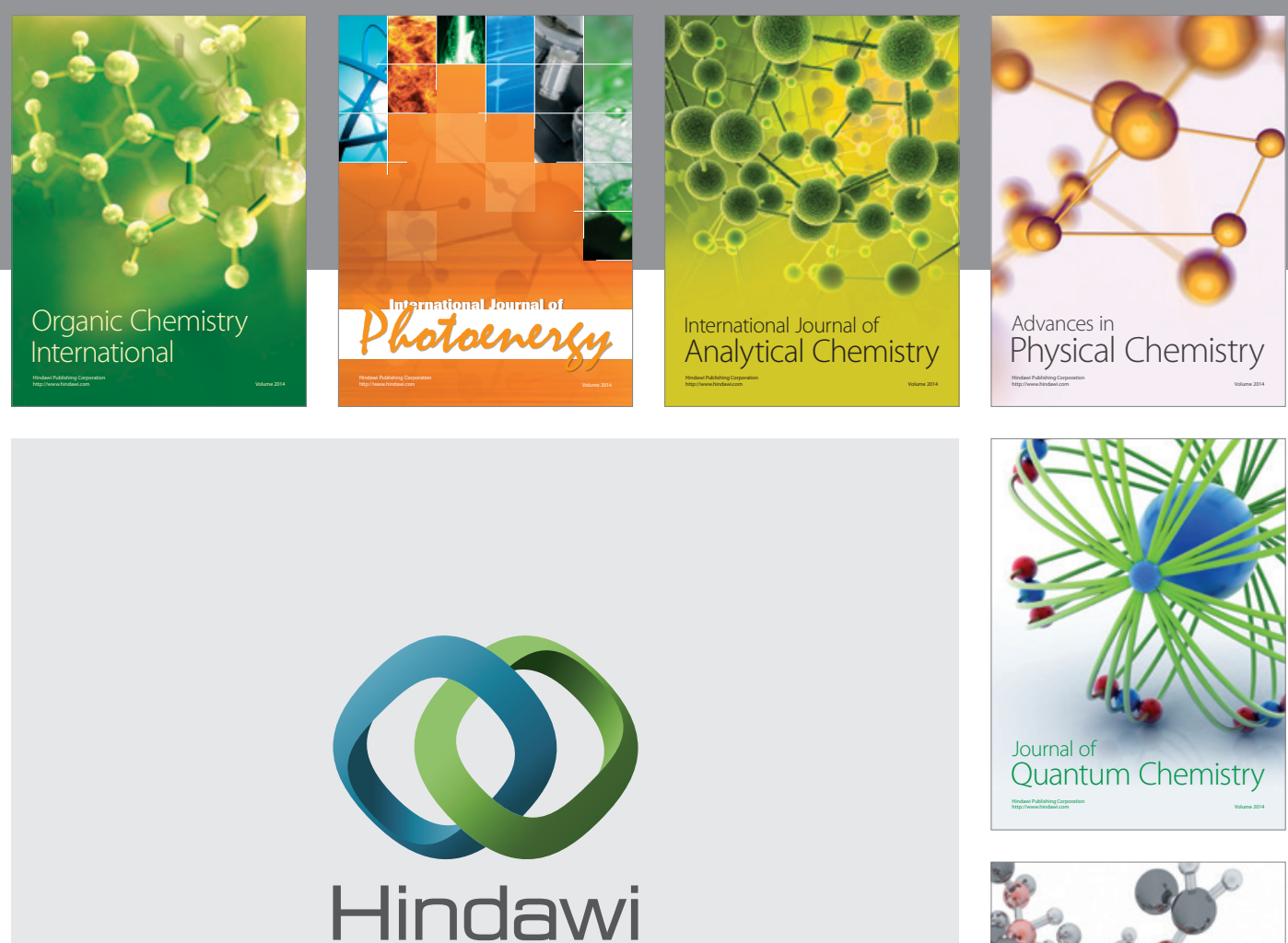

Submit your manuscripts at

http://www.hindawi.com

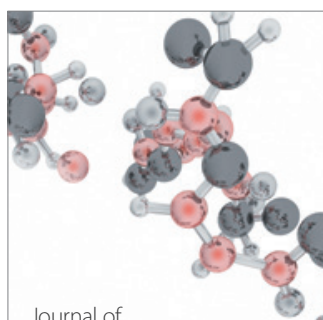

Analytical Methods

in Chemistry

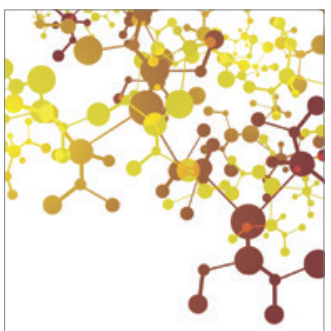

Journal of

Applied Chemistry

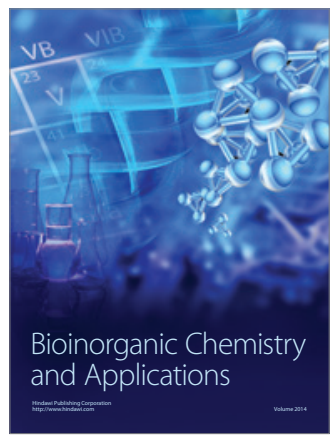

Inorganic Chemistry
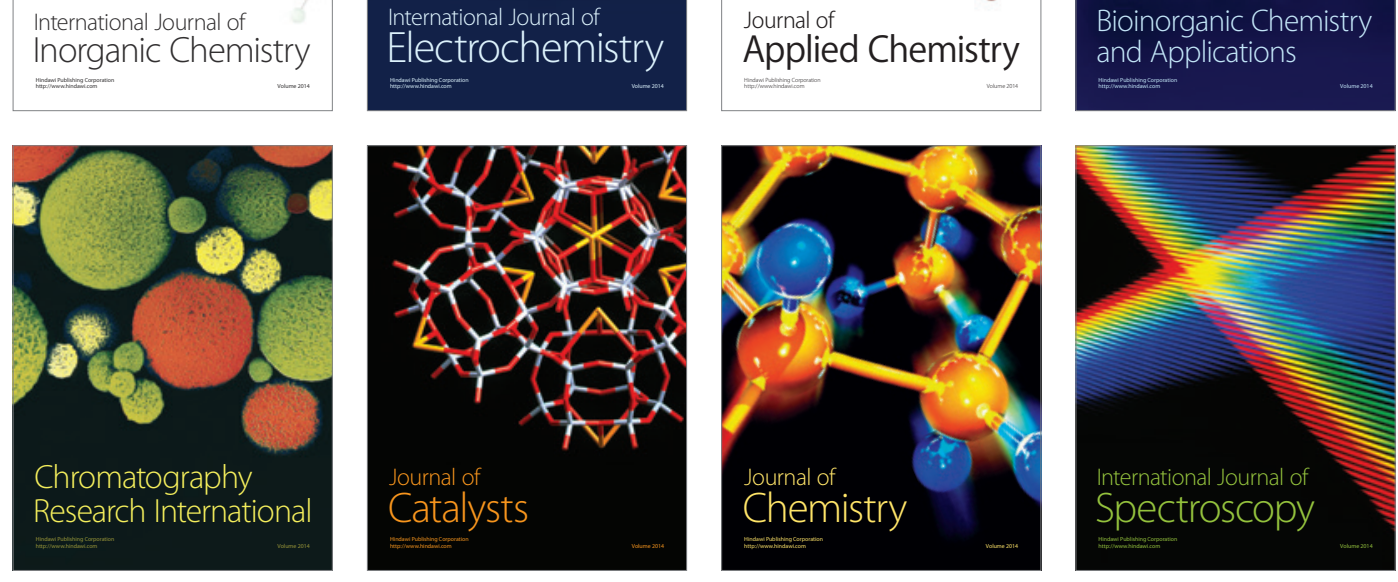